\title{
FYVE, RhoGEF and PH Domain-Containing Protein 5
}

National Cancer Institute

\section{Source}

National Cancer Institute. FYVE, RhoGEF and PH Domain-Containing Protein 5. NCI

Thesaurus. Code C105933.

FYVE, RhoGEF and PH domain-containing protein 5 (1462 aa, 160 kDa) is encoded by the human FGD5 gene. This protein plays a role in both signal transduction and the reorganization of the actin cytoskeleton. 